\title{
The Age of Non-Invasive Measurements: Echocardiographic Equations Methods to Determine Variables in the Pulmonary Vascular Reactivity Test
}

\author{
Tania T Muñoz-Hernández*, Elizabeth Hirschhaut-Schor, Simon F Tovar-Blanco and Guillermo J Lara-Boada \\ Department of Cardiology, Military Hospital “Dr. Carlos Arvelo”, Caracas, Venezuela
}

*Corresponding author: Tania T Muñoz-Hernández, Echocardiography Unit, Department of Cardiology, University Hospital “Dr. Carlos Arvelo", Av. Jose Angel Lamas, San Juan Parish, Caracas, Venezuela, E-mail: electroshock_2010@hotmail.com

Received: 09 Oct, 2019 | Accepted: 15 Nov, 2019 | Published: 21 Nov, 2019

Citation: Muñoz-Hernández TT, Hirschhaut-Schor E, Tovar-Blanco SF, Lara-Boada GJ (2019) The Age of Non-Invasive Measurements: Echocardiographic Equations Methods to Determine Variables in the Pulmonary Vascular Reactivity Test. J Surg Open Access 5(6): dx.doi. org/10.16966/2470-0991.200

Copyright: (c) 2019 Muñoz-Hernández TT, et al. This is an open-access article distributed under the terms of the Creative Commons Attribution License, which permits unrestricted use, distribution, and reproduction in any medium, provided the original author and source are credited.

\begin{abstract}
Introduction and objectives: Right Heart Catheterization (RHC) is a gold method to perform the Pulmonary Vascular Reactivity Test (PVRT), however echocardiography has proven effective in estimating different hemodynamic variables. This study to demonstrate that with the Doppler echocardiographic index: Tricuspid Regurgitation Maximum Velocity (TRV)/Time-Velocity Integral of the Right Ventricle Outflow Tract (TVI ${ }_{\text {rvot }}$ ) we will obtain a Pulmonary Vascular Resistance Value (PVR) comparable to the invasive method. We evaluate its applicability in the PVRT.

Methods: Prospective, double-blind, observational study in 30 patients, performed in 2 stages: A) We obtained simultaneous measurements of PVR

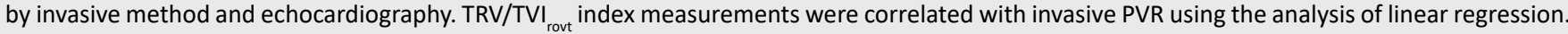
An equation was modeled to calculate PVR in Wood Units (WU) by echocardiography; the results were compared with invasive RVP measurements using the Bland-Altman analysis. B) TRVP was performed by simultaneous measurement of PVR and Pulmonary Arterial Mean Pressure (MPAP) with the echocardiographic and invasive method. We use the equation formulated by Abbas (RVPa) and another modified one proposed in this study (RVPt).

Results: In the first stage, the TRV/TVI rotv ratio correlated well with invasive PVR measurements $\left(R^{2}=0.92\right)$. The Bland Altman analysis using $R V P=10 \times$ VRT/TVI ${ }_{\text {rvot }}+0.36$ showed satisfactory agreement limits (mean $\pm 0.36, L: 0.12-0.61$ ). In the TRVP there was a high correlation of PVR between the two methods using the two equations. We also found high correlation with MPAP.
\end{abstract}

Conclusions: The Doppler echocardiogram offers a reliable and non-invasive method to measure the PVR and MPAP in the PVRT.

Keywords: Right heart catheterization; Wood units; Doppler echocardiography; Pulmonary vascular reactivity test

Abbreviations and Acronyms: TRV-Peak Tricuspid Regurgitant Velocity; TVI rvot-Right Ventricular Outflow Tract Time-Velocity Integral; PVRTPulmonary Vascular Reactivy Test; MPAP-Mean Pulmonary Arterial Pressure; PH-Pulmonary Hypertension; PVR (SG)-Pulmonar Vascular Resistence (Swan Ganz)

\section{Introduction}

Pulmonary vascular resistance is a hemodynamic variable very useful for the management of patients with advanced pathologies cardiovascular and pulmonary, to evaluate the therapeutic response in patients with congestive heart failure $[1,2]$. Evaluation of patients candidates for cardiac and liver transplant [3-7], is a prognostic parameter for patients with congenital diseases [8], is considered a critical parameter for evaluating PH independent of etiology [9]. The PVR is calculated invasively by the relation of the pressure gradient and the flow transpulmonar [10], Abbas and collaborators $[11,12]$ proposed to estimate the measurement echocardiographic of the PVR by the relation TRV/TVI ${ }_{\text {rvot }}$ representing the method most used currently, among others proposed for its calculation [13-18]. On the other hand, the PVRT has very precise indications according to the European Society Cardiology guidelines [9] for the diagnosis, treatment and prognosis of the $\mathrm{PH}$. Right catheterization is considered as the gold standard for the definitive diagnosis of PAH and the method of choice for PVRT [19]. There aren't reports of studies comparing in the PVRT simultaneous measurements of PVR and MPAP with the invasive method and the Echocardiography Doppler. In this investigation we raised 3 objectives: 1) Revalidate Abbas's equation in a group of patients [20] with indication of Right Heart Catheterization (RHC) diagnosis. 2) Compare the invasive and non-invasive measurements of MPAP and PVR in a group of patients who underwent the PVRT and verify the effectiveness of the echocardiographic measurements. 3) Demonstrate in this group of patients the utility and efficiency of a novel Echocardiographic equation to calculate the PVR when compared with the Abbas's equation [10] and the RHC. 


\section{Methods}

\section{Population and sample}

It's a prospective, double-blind, observational study that was divided into two stages, the first part was selected 20 patients. 10 patients with admission to Intensive Care Unit (ICU) and placement of Swan Ganz catheter for presenting medical pathologies that merited measurement of hemodynamic variables; 10 patients in the Center's cardiology department consultation or hospitalization, with indication of right catheterization to confirm diagnosis clinical and echocardiographic of $\mathrm{PH}$. No distinction was made for age group, sex, comorbidity, or medication was omitted (Table 1). All patients entered our center in the period from February to August 2008.

\section{Exclusion criterion}

Regurgitation tricuspid $>2+$. The clinical, hemodynamic and demographic characteristics are shown in table 1.

In the second part of the study were included 11 patients referred to the medical consultation, of pneumonology, pediatric cardiology and adult cardiology of the same center with presumptive diagnosis of $\mathrm{pH}$, of different etiology, degree of severity and echocardiographic criteria for Perform the pulmonary vascular reactivity test. These patients were studied from July to December 2009 (Table 2).

Exclusion criterion: Patients with hemodynamic instability, chronic or acute hypoxemia, coagulation disorders.

One patient was removed from the study because of the inability to perform measurements with the catheter and in 2 patients only one measurement was made. All patients in the Department of Cardiology (both stages) signed informed consent. Table 3 shows the values obtained in the 10 patients of the PVRT of the TRV/TVI rvot $_{\text {index, the }}$ first Abbas equation, applying the Abbas algorithm and RHC. Table 4 shows the values obtained from MPAP calculated with the Chemla equation and RHC at times 0 (t0), 30 minutes, ( $\mathrm{t} 30)$ and recovery $(\mathrm{tR})$ of the test.

Table 1: Clinical, hemodynamic and demographic characteristics of patients (group 1).

\begin{tabular}{|l|c|}
\hline SEX (M/F) & $15 / 5$ \\
\hline AGE mean (RANGE) years & $48(21-78)$ \\
\hline Ejection fraction mean (RANGE) & $55(30-75)$ \\
\hline MPAP mean (RANGE) mmHg & $20(13-30)$ \\
\hline Pulmonary capillary pressure & $12(6-20)$ \\
\hline Mean (RANGE) & 12 \\
\hline $12 \mathrm{mmHg}$ & 7 \\
\hline $13-19 \mathrm{mmHg}$ & 1 \\
\hline$\geq 20$ mmHg & $1.5(1.22-2.02)$ \\
\hline PVR (cat) mean (RANGE) (WU) & $1.7(1.28-2.95)$ \\
\hline PVR S.G mean (RANGE) & 1 \\
\hline Diagnostics & 1 \\
\hline Aortic valve replacement+revascularization & 1 \\
\hline Mitral valve replacement & 6 \\
\hline Resection of Myxoma+revascularization & 1 \\
\hline Myocardial revascularization & 3 \\
\hline Aorticaneurysm correction & 6 \\
\hline Ventricular septal defect & 1 \\
\hline Interatrial Communication & \\
\hline Dilatation of the pulmonary artery trunk & \\
\hline
\end{tabular}

Table 2: Clinical, hemodynamic and demographic characteristics of patients (group 2).

\begin{tabular}{|l|c|}
\hline SEX (M/F) & $5 / 5$ \\
\hline AGE mean (RANGE) years & $47(27-63)$ \\
\hline Ejection fractions mean (RANGE) (\%) & $55(30-75)$ \\
\hline MPAP mean (RANGE) mmHg & $27(17-62)$ \\
\hline Pulmonary capillary pressure & \\
\hline Mean (RANGE) mmHg & $12(8-31)$ \\
\hline$\leq 12$ mmHg & 8 \\
\hline $13-19$ mmHg & 0 \\
\hline$\geq 20$ mmg & 2 \\
\hline PVR (cat) Mean (RANGE) (WU) & $6.29(1.25-16.4)$ \\
\hline PVR (echo) mean (RANGE) (WU) & $3.20(1.64-8.16)^{*}$ \\
\hline CO (Lt/min) mean (RANGE) & $4(3.2-5.2)$ \\
\hline RVD mean(RANGO) mm & $34(22-55)$ \\
\hline TVI ${ }_{\text {rvot } \text { Mean(RANGE) cm }}$ 13.72 (6-22) \\
\hline Diagnostics & \\
\hline Interatrial Communication & 2 \\
\hline Valvular heart disease type severe mitral insufficiency & 2 \\
\hline COPD+ PH severe & 3 \\
\hline $\begin{array}{l}\text { Aortic and mitral valve heart disease, double lesion } \\
\text { type, both mild }\end{array}$ & 1 \\
\hline Ventricular septal defect & 1 \\
\hline Dilatation of the pulmonary artery trunk & 1 \\
\hline
\end{tabular}

COPD=Chronic Obstructive Pulmonary Disease; $\mathbf{P A H}=\mathrm{Pulmonary}$ Arterial Hypertension; $\mathbf{P H}=$ Pulmonal Hypertension; $\mathbf{P V R}_{\text {cat }}=$ Pulmonary Vascular Resistance by Catheterization; $\mathbf{P V R}_{\text {eco }}=$ Pulmonary Vascular Resistance by Echocardiographic; RVD=Right Ventricular Diameter; WU=Wood Units *Calculation obtained by the equation proposed by Abbas: PVR echo $=T V R /$ $\mathrm{TVI}_{\text {rvot }} \times 10+0.16$

Table 3: Invasive and non-invasive measurements of Pulmonary Vascular Resistance in the pulmonary vascular reactivity test.

\begin{tabular}{|c|c|c|c|}
\hline TRV/TVI $_{\text {rvot }}$ BASAL & PVR (eco) BASAL* & PVR (algorithm) & PVR (cat) BASAL \\
\hline 0.14 & 1.56 & 1.56 & 1.25 \\
\hline 0.16 & 1.76 & 1.76 & 1.8 \\
\hline 0.22 & 2.36 & 2.36 & 2.16 \\
\hline 0.23 & 2.46 & 2.46 & 3.8 \\
\hline 0.24 & 2.56 & 2.56 & 4.18 \\
\hline 0.25 & 2.66 & 2.66 & 4.2 \\
\hline 0.36 & 3.76 & 8.9 & 11.5 \\
\hline 0.38 & 3.96 & 7.36 & 16.4 \\
\hline 0.53 & 5.46 & 10 & 10.5 \\
\hline 0.8 & 8.16 & 13.33 & 14.37 \\
\hline
\end{tabular}

*Obtained from the Abbas equation $\mathrm{PVR}_{\text {echo }}=10 \times \mathrm{TRV} / \mathrm{TVI}_{\text {rvot }}+0.16$.

The study was approved by the Bioethics and Medical Ethics Committee of the medical institution.

\section{Echocardiography}

The Doppler and two-dimensional measurements were performed with the Philips Sonos 7500 S3 and Philips IE33 SE1 equipment According to American Society Cardiology guidelines [20]. The TRV/TVI $_{\text {rvot }}$ index was determined by Doppler echocardiography using the view of the short parasternal axis at the level of large vessels. The TVI ${ }_{\text {rvot }}(\mathrm{cm})$ was obtained with pulsed Doppler by 
Table 4: Invasive and non-invasive measurements of MPAP during stages t0, t3 and recovery (tR) from PVRT.

\begin{tabular}{|c|c|c|c|c|c|}
\hline $\mathrm{MPAP}_{\text {echo }} *$ to & MPAP Ct t0 & $\mathrm{MPAP}_{\text {echo }} \mathrm{t} 30$ & MPAP Ct t30 & MPAP $_{\text {echo }} \mathrm{R}$ & MPAPCt R \\
\hline 25 & 17 & & & & \\
\hline 30 & 23 & & & & \\
\hline 61 & 62 & 56 & 57 & 56 & 57 \\
\hline 49 & 61 & 57 & 60 & 53 & 54 \\
\hline 64 & 54 & 47 & 48 & 47 & 48 \\
\hline 34 & 33 & 26 & 27 & 28 & 30 \\
\hline 33 & 32 & 28 & 30 & 27 & 33 \\
\hline 21 & 18 & 16 & 16 & 15 & 14 \\
\hline 35 & 27 & 25 & 22 & 25 & 22 \\
\hline 50 & 54 & 50 & 51 & 63 & 64 \\
\hline
\end{tabular}

$* \mathrm{MPAP}_{\text {echo }}=0.61 \times \mathrm{SPAP}+1.95$

placing the sample volume at a level of the proximal $5 \mathrm{~mm}$ of the pulmonary valve just before the beginning of the closing [20], and the TRV $(\mathrm{m} / \mathrm{s})$ was obtained with continuous Doppler placed in the regurgitating flow tricuspid at the valve level. It was also determined this variable in the view 4 cameras with the intention of getting the maximum velocity possible. With this and the Right Atrial Pressure (RAP), using the modified Bernoulli equation were obtained values of Systolic Pulmonary Arterial Pressure (SPAP) $[21,22]$ to then calculate the MPAP with the equation proposed by Chemla D, et al. [23].

In both parts of the work, measurements were performed 3 times and averaged. The measurement of the Ejection Fraction (EF) was determined by the method of Simpson [20]. Measurement of the Right Ventricle Diameter (RVD) was done in the long parasternal axis by evaluating the proximal or subvalvular RVOT measured from the angle formed by the junction of the aortic ring with the basal septum and the free wall of the RV at the end of the diastole [20].

\section{Right catheterization}

In the intensive care unit, patients in the first group [10] were placed Swan Ganz catheters arrow, 6 or 7 French (F) to obtain pulmonary pressure and flow measurements. The Seldinger technique was used to approach the Internal Jugular Vein (IJV) or Subclavia [24]. Cardiac Output (CO) was determined by the technique of thermodilution and PVR with the equation: PVR: MPAP-PCP/CO [24-27]. In the Hemodynamics laboratory, Judkins catheter $6 \mathrm{~F}$ was used in all patients, with femoral venous approach, guided by fluoroscopy. The PVRT was performed in the hemodynamics laboratory with central venous approach and placing, Swan Ganz catheter. 20 micrograms of inhaled illoprost were administered with simultaneous measurements of the variables of TRV, TVI ${ }_{\text {rvot }}$, MPAP. CO and Pulmonary Capillary Pressure (PCP) were obtained by thermodilution and wedging respectively. Measurements were performed at $0,5,10,15,30$ minutes and recovery $[28,29]$.

We take as a criterion of positivity of the PVRT a decrease $>20 \%$ of the MPAP and the PVR without diminishing the CO [30].

\section{Statistical analysis}

We used software MedCalc statitic 2019 version 18.11.3/14.0 SPSS and Real statistics Excel. Performed linear regression analysis between the invasive method PVR measured in Woods Units (WU), and noninvasive TRV/TVIrvot in both parts of the study. This analysis was also used between the values of PVR obtained by echocardiography using the algorithm of Abbas AE, et al. [12] and the equation proposed in this work. The Pearson correlation coefficient was determined in all cases, and a regression equation was derived. The calculated values were then studied using the Bland-Altman analysis. Using the ROC curve, a cutting value was obtained for TRV/TVI rvot $_{\text {and PVR }}$ (catheterization) to predict high values of $\mathrm{PVR}>4.5 \mathrm{WU}$ with balanced values of sensitivity and specificity [31].

The images were reassessed to quantify the reliability of the intraobserver and interobserver. The Intraclass Correlation Coefficient (ICC) was determined for variability inter and intraobservers; the relationship between the force of agreement and ICC were analyzed. The Kappa coefficient was also estimated to assess the degree of interobserver concordance.

\section{Results}

The first group found analyzed a PCP greater than $12 \mathrm{mmHg}$ was found in 7 patients. 10 patients presented left heart disease of different etiology (Table 1). The linear correlation analysis between $\mathrm{PVR}_{\text {cath }}$ and TRV/TVI ${ }_{\text {rvot }}$, showed high correlation $\left(\mathrm{R}^{2}=0.95 .95 \% \mathrm{CI}\right)$. The equation derived from linear regression was $\mathrm{PVR}_{\text {echo }}=10 \times \mathrm{TRV} / \mathrm{TVI}_{\text {rvot }}+0.36$ (Figure 1).

Applying the analysis of Bland-Altman, the values of PVR of this equation showed satisfactory limits in accordance with the $\mathrm{PVR}_{\text {cath' }}$, with average value 0.36 (SD: 0.13-0.6) (Figure 2).

In the second group analyzed (Table 2), 8 of them presented PCP equal or less than $12 \mathrm{mmHg}$, being varied the subgroups within the classification of PH accepted by ESC: 1.4.4. Congenital heart disease: interatrial communication [2], Interventricular communication [1], 2.3. Valvular: Mitral valvulopathy type severe insufficiency [2], Aortic and mitral valvulopathy type double lesion, both mild [1]. 3.1. Severe COPD+Severe PH [3] and 3.5 Diseases of pulmonary development: Dilation of the pulmonary artery trunk [1]; unlike the first group, most patients reported high PVR values for being candidate patients of the PVRT (Table 2).

In the second stage of the study, the analysis of linear correlation between $\mathrm{PVR}_{\text {cath }}$ and TRV/TVI $\mathrm{rvot}_{\text {rvo }}$ basal showed good correlation $\left(\mathrm{R}^{2}=0.70,95 \% \mathrm{CI}\right)$ that was exceeded by excluding the highest values of $\mathrm{PVR}_{\text {cath }}\left(\mathrm{R}^{2}=0.92,95 \% \mathrm{CI}\right)$ (Figures 3 and 4 ). 


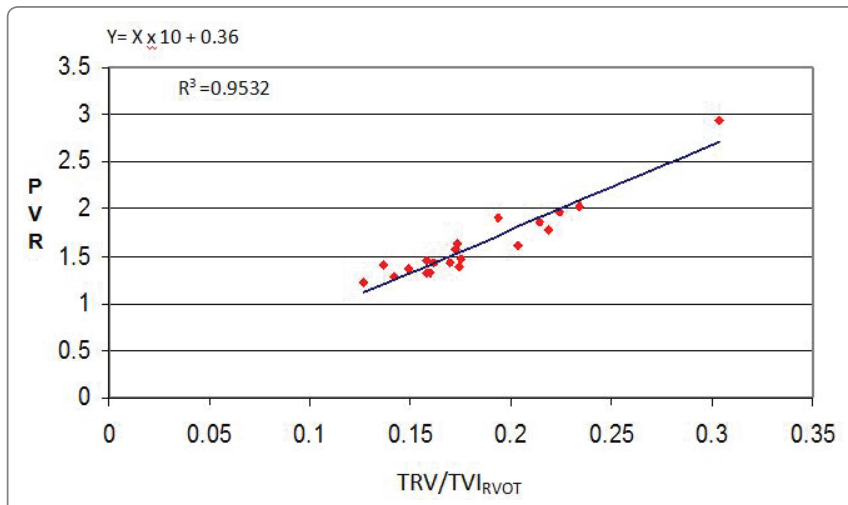

Figure 1: Linear regression analysis between PVR by right catheterization and the ratio $\mathrm{TRV} / \mathrm{TVI}_{\mathrm{RVOT}}$ obtained by Doppler echocardiography.

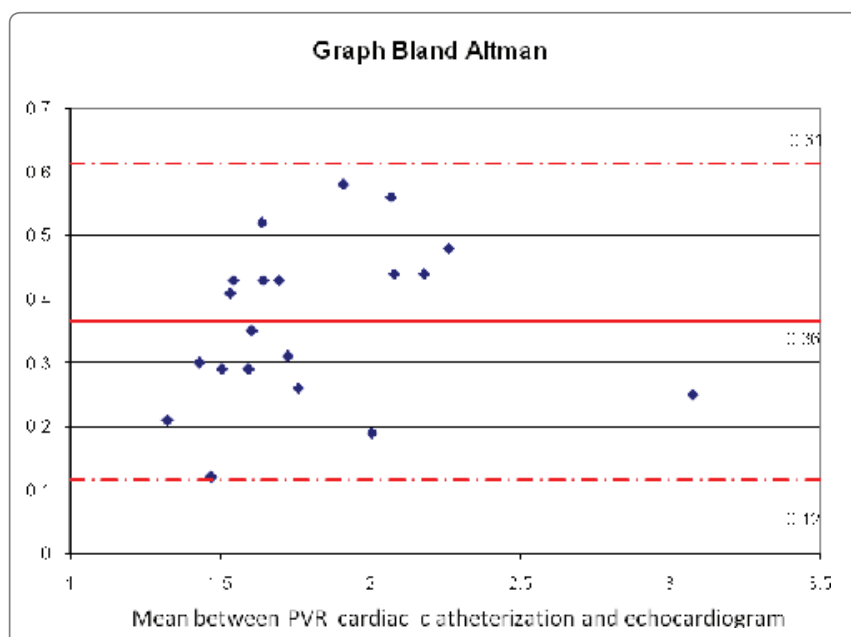

Figure 2: Analysis of Bland-Almant showing the limits of agreement between PVR ${ }_{\text {СATH }}$ and PVR ${ }_{E C H O}$.

There was also a report of high correlation between the two methods by excluding the 3 highest values at 30 minutes of the test and in the recovery stage $\left(\mathrm{R}^{2}=0.89\right.$ in both cases) (Figures 5 and 6 ). Prior to exclusion, the correlation coefficient was $\mathrm{R}^{2}=0.56$ with the first equation of $A b b a s$ and $R^{2}=0.64$ when applying its algorithm (Figure 7).

The Youden's index was estimated obtaining a cut value in the ratio TRV/TVI ${ }_{\text {rvot }}$ of 0.24 provides $95 \%$ sensitivity and $100 \%$ of specificity to determine $\mathrm{PVR}_{\text {cath }}$ of $4.67 \mathrm{WU}$ in the basal stage of the PVRT (Figure 8). Receiver Operating Characteristic (ROC) curve. In addition to the above, it shows AUC of $1.95 \%$ confidence interval between $0.692-1$ and significance nivel $\mathrm{p}<0.0001$ (Figure 9).

We found very high correlation $\left(\mathrm{R}^{2}=0.97\right)$ when comparing values obtained from PVR by the Abbas algorithm (if TRV/TVI ${ }_{\text {rvot }}<0.275$ index, $\mathrm{PVR}_{\text {echo }}=\mathrm{TRV} / \mathrm{TVI}_{\mathrm{rvot}} \times 10+0.16$. If TRV $/ \mathrm{TVI}_{\mathrm{rvot}} \geq 0.275$ index, PVRABBAS $\left.=\mathrm{TRV}^{2} / \mathrm{TVI}_{\text {rvov }} \times 5\right)$ and the equation proposed in this work: $\mathrm{PVRt}=\left(\mathrm{TRV} \times \mathrm{RVD} / \mathrm{TVI}_{\text {rvot }}\right) \times$ Cardiac output correction factor (cfCO TVI $\mathrm{rvot}_{\text {) }}$ (Figure 10). The correlation obtained when both equations were compared with the values of $\mathrm{RHC}$ were high $\left(\mathrm{R}^{2}=0.78\right.$ and $\mathrm{R}^{2}=0.84$, respectively) (Figures 11 and 12) Bland Altman's analysis showed satisfactory agreement limits between the methods with average differences similar between the methods (Figures 11 and 12).

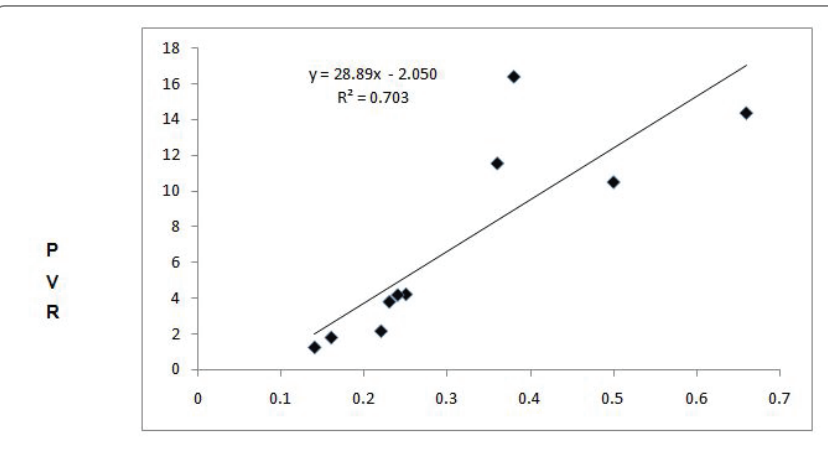

TRVITVI ${ }_{\text {RVOT }}$ basal

Figure 3: Linear regression analysis between the PVR ${ }_{\text {CATH }}$ and the TRV/ $\mathrm{TVI}_{\mathrm{RVOT}}$ relation at the beginning of the PVRT.

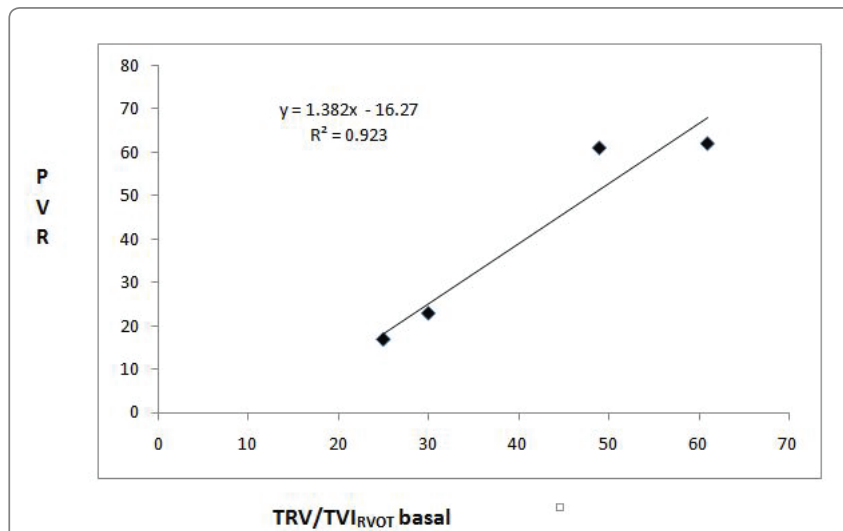

Figure 4: Linear regression analysis between the $\mathrm{PVR}_{\text {СATH }}$ and the baseline TRV/TVI ${ }_{\mathrm{RVOT}}$ ratio after excluding the 4 highest values obtained by catheterization.

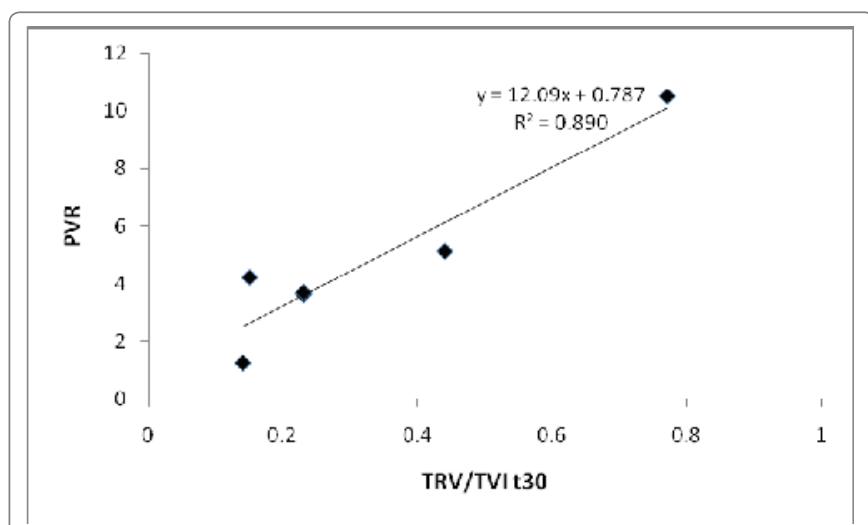

Figure 5: Linear regression analysis between the PVR ${ }_{\text {CATH }}$ and the TRV/ $\mathrm{TVI}_{\text {RVOT }}$ ratio obtained 30 minutes after the PVRT after excluding the 3 highest values.

We obtained MPAP values by echocardiography from the formula proposed by Chemla D, et al. [23]: PMAP $=0.61 \times \mathrm{PSAP}+1.95$. High correlation was found in the linear regression analysis between

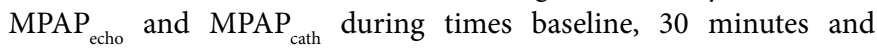
recovery ( $\mathrm{t} 0$, $\mathrm{t} 30$ and $\mathrm{tR})\left(\mathrm{R}^{2}=0.87,0.98 .0 .99\right)$ (I.C. 95\%) (Figure 13). Bland Altman's analysis showed satisfactory concordance limits in all 


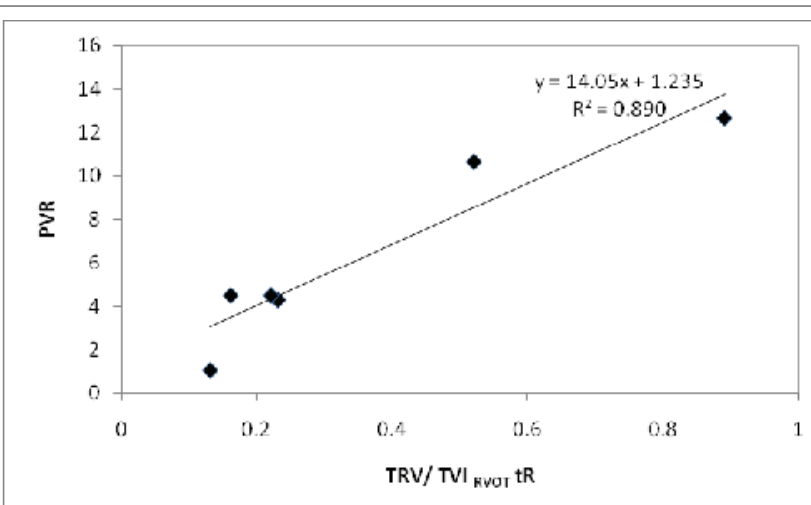

Figure 6: Linear regression analysis between the invasive PVR and the ratio TRV/TVI ${ }_{\text {RVOT }}$ obtained in the recovery stage of the PVRT and after excluding the 3 highest values.

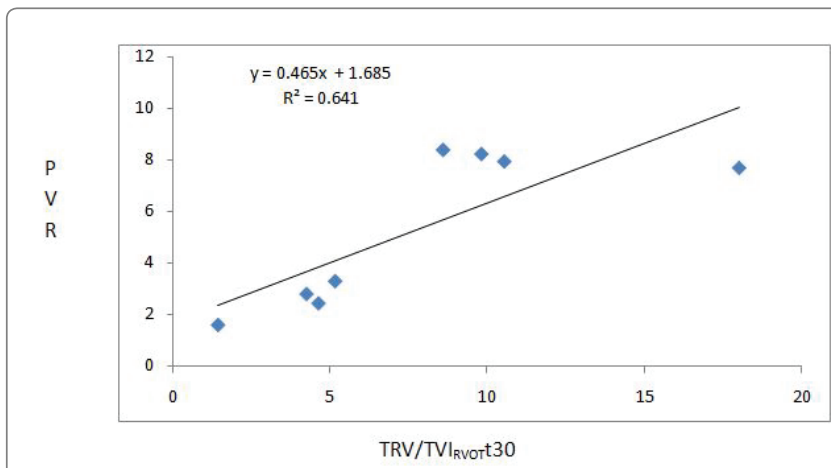

Figure 7: Linear regression analysis between $\mathrm{PVR}_{\mathrm{CATH}}$ and the VRT/ $\mathrm{ITV}_{\text {RVOT }}$ relationship obtained in step t30 of the PVRT when applying the Abbas algorithm.

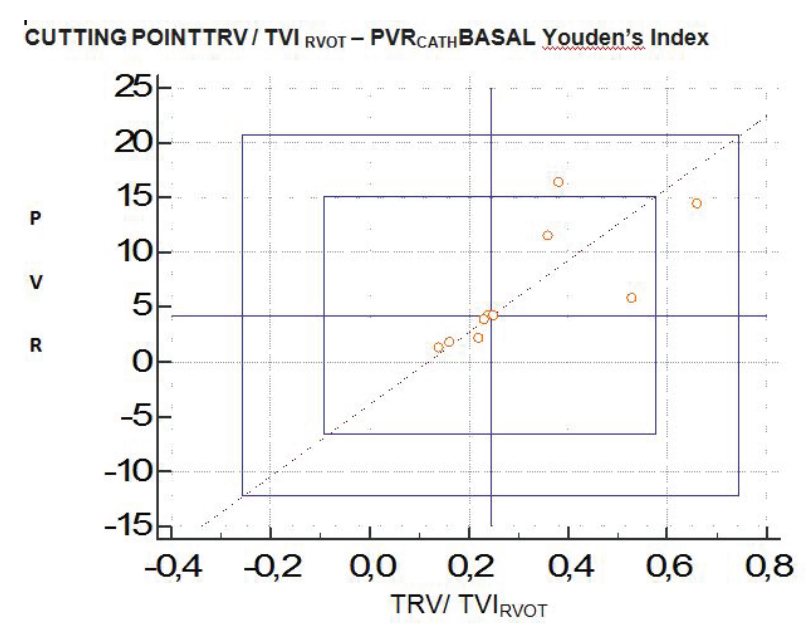

Figure 8: Cut-off value 0.24 gave $95 \%$ sensitivity and $100 \%$ specificity to determine RVP ${ }_{\text {CATH }}>4.67 \mathrm{UW}$ in the basal stage of PVRT.

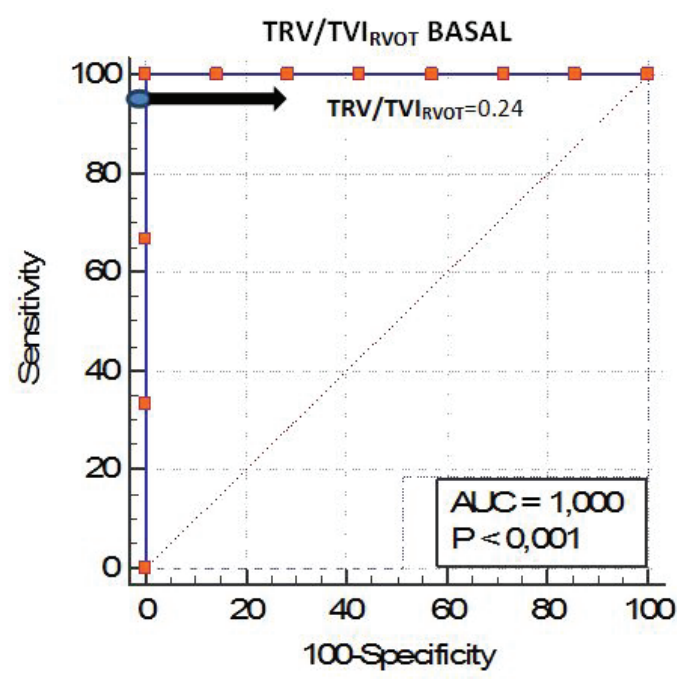

Figure 9: Receiver Operating Characteristic (ROC) curve. A TRV/TVI ${ }_{\text {RVOT }}$ ratio of 0.24 (blue) and provided the best-balanced sensitivity and specificity to determine patients with PVR $>4.67 \mathrm{WU}$ (areas under the curve $[A U C])$ of 1 .
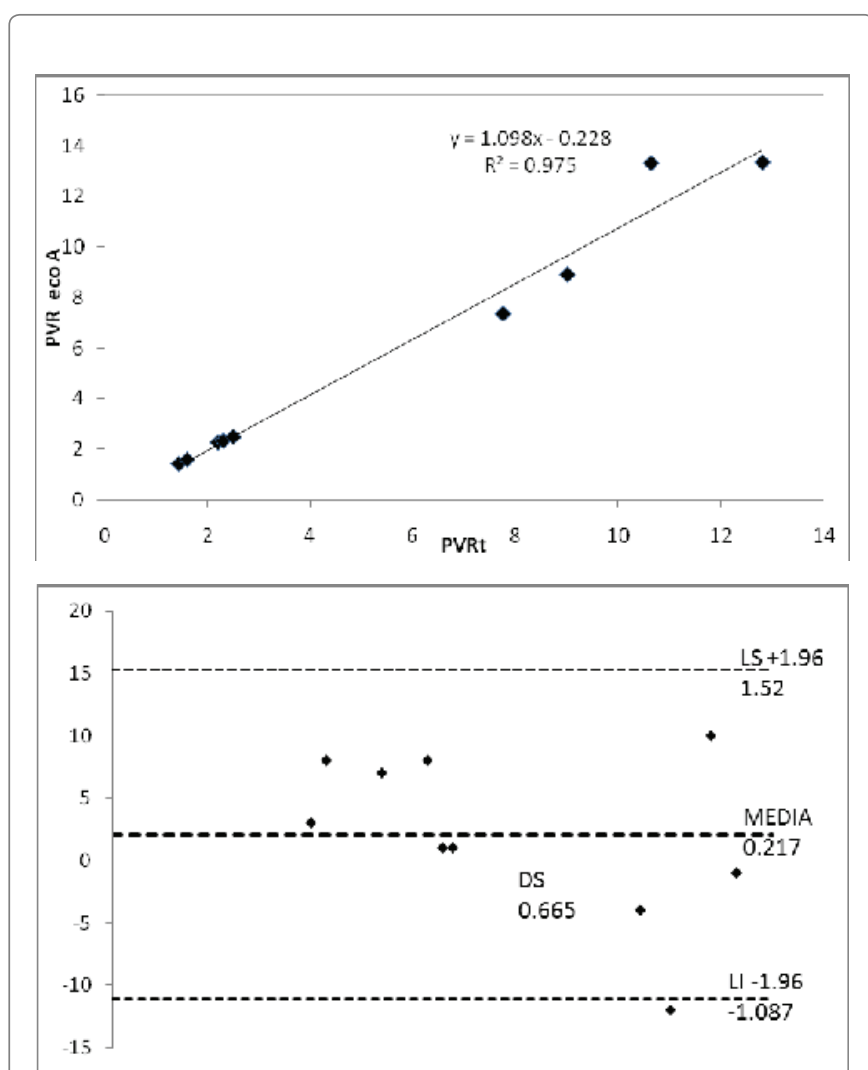

Figure 10: Linear regression analysis and Bland Atlman between the PVR obtained by the Abbas algorithm and the equation proposed in this study (PVRt). 

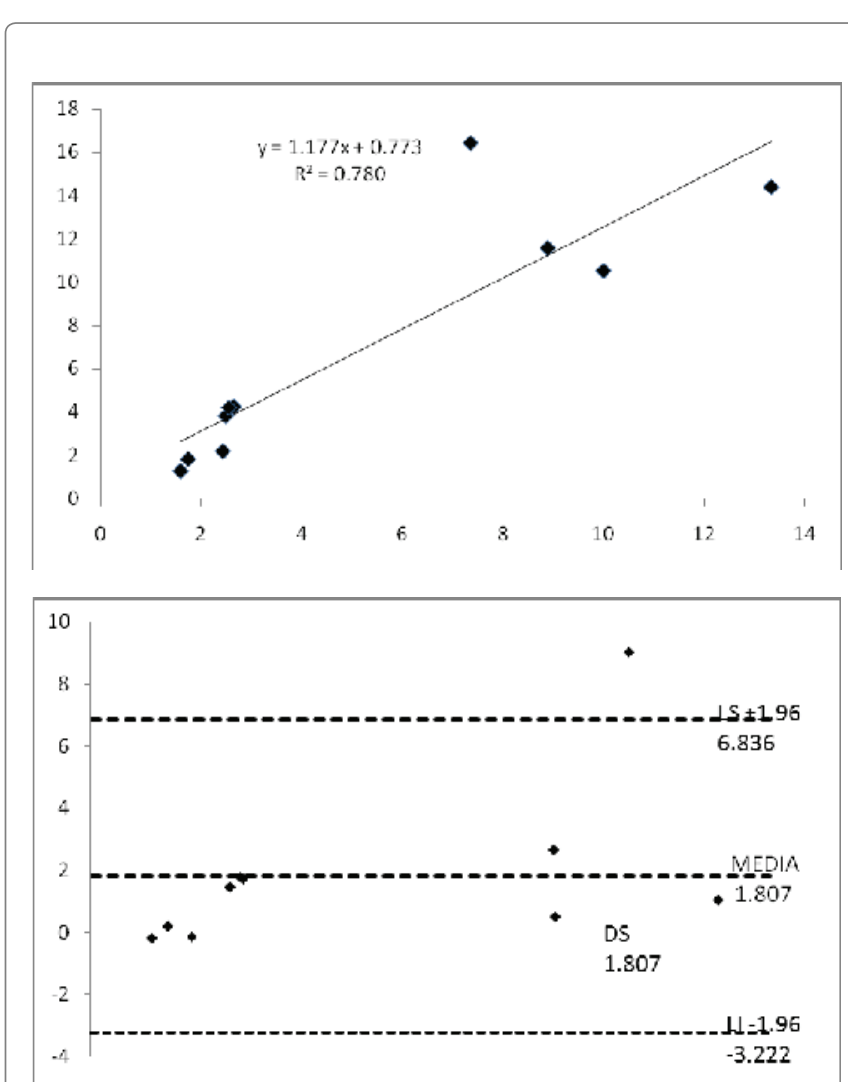

Figure 11: Linear regression analysis and Bland Altman between the PVR obtained by the Abbas algorithm (PVRa) and cardiac catheterization.

cases, with average differences between the RHC of: $2,-0.75$ and -1 (Figure 14). The TRVP reported negative in all patients. The CCI was 0.78 between observers and 0.90 observers with excellent agreement force. The Kappa coefficient inter observer was 0.83 with an almost perfect concordance force.

\section{Discussion}

15 years have passed since Abbas AE, et al. [11] published a simple Doppler echocardiographic equation: $\mathrm{PVR}=0.16+\mathrm{TRV} / \mathrm{TVI}_{\mathrm{rvot}} \times 10$. As we know, the PVR is directly related to the Pressure Gradient $(\Delta \mathrm{P})$ and inversely with cardiac output (CO), according to this author; its equivalents echocardiographic would be represented by the TRV as a measure of pressure gradient and TVI as a Cardiac flow measurement. Unfortunately the work presented had a great limitation because it excluded all patients with moderate and severe tricuspid regurgitation representing the population that could be most favored. In successive years, emerged publications aimed at giving validity to this equation [32-36], discuss its content 16-18 or establishing different approaches and hemodynamic variables for the calculation of PVR [13-16,37,38].

One of the works proposed by another variable echocardiographic to determine the PVR is that presented by Gurudevan SV, et al. [14], they concluded that there is an inverse correlation between systolic velocity of Tricuspid Annulus ( $\mathrm{tSm}$ ) and PVR, determining that a velocity $<10 \mathrm{~cm} / \mathrm{s}$ equals a $\mathrm{PVR}_{\text {cath }}>12.5 \mathrm{UW}$. Haddad F, et al. [13] proposed an index to obtain $\mathrm{PVR}_{\text {echo }}=\mathrm{SPAP} /\left(\mathrm{HR} \times \mathrm{TVI}_{\text {rvot }}\right)$ where a cut value of 0.076 provided $86 \%$ sensitivity and $82 \%$ specificity to determine IPVR $>15 \mathrm{WU} / \mathrm{m}^{2}$. He also mentioned that patients with
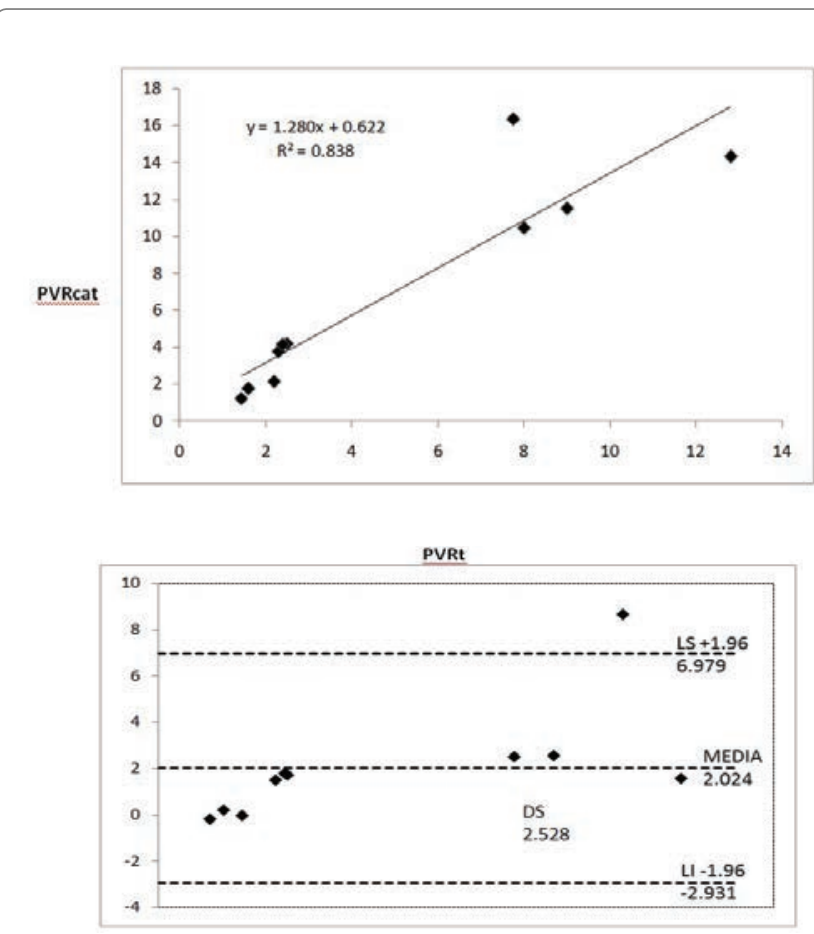

Figure 12: Analysis of linear regression and Bland Altman between the PVR obtained by the equation of this work (PVRt) and cardiac catheterization.

elevated values of PVR didn't correlated well using the equation proposed by Abbas $\left(R^{2}=0.46\right)$.but with the lowest values yes.

An index proposed by Scapellato $F$, et al. [15], requires the measurement of the Pulmonary Preeyective Period (PPEP), Pulmonary Acceleration Time (PAT) and Total Systolic Time (TST) $(\mathrm{PVR}=\mathrm{PPEP} / \mathrm{PAT} / \mathrm{TST}$; reported high correlation with PVR obtained by catheterization Cardiac $\left(R^{2}=0.96\right)$. An index $>2.6$ predicts a $P V R>2.5$ WU when the resistances are between 0-8 WU. This equation didn't apply in the work of Haddad F, et al. [13] by low correlation $\left(\mathrm{R}^{2}=0.30\right)$.

Vlahos AP, et al. [32] conducted a prospective study in 12 patient's candidates for liver transplantation and obtaining PVR by right catheterization. They analyzed the index TRVTVI rvot $_{\text {and TRV/TVI }}$ corrected by the diameter of the RVOT, finding that both correlated well with $P_{\text {cath }}\left(R^{2}=0711\right.$ and $R^{2}=0731$, respectively), even in patients with elevated values of PVR. They concluded in their study that the

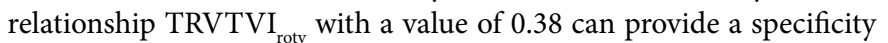
of $100 \%$ for PVR of $8 \mathrm{WU}$.

Opotoswky AR, et al. [17], in 2013 published a paper where they derive 2 equations to estimate the PVR from the relationship between SPAP and TVI rvot , validated these equations and compared with the equation of Abbas AE, et al. [11] (model 1). The derived models were: $\mathrm{PVR}=1.2 \times \mathrm{SPAP} / \mathrm{TVI}_{\mathrm{rvot}}($ Model 2$)$ and $\mathrm{PVR}=\left(\mathrm{SPAP} / \mathrm{TVI}{ }_{\mathrm{rvot}}\right)+3$, if the systolic notch is present (Model 3). They found that model 1 consistently underestimated the PVR estimated by catheterization, especially for those with high PVR. The derivative models showed no bias, model 3 was best correlated with $\mathrm{PVR}_{\text {cath }}\left(\mathrm{R}^{2}=0.80\right.$ vs $\mathrm{R}^{2}=0.73$ and $\mathrm{R}^{2}=0.77$ for Models 1 and 2, respectively). This approach caused discomfort in Abbas AE, et al. [11], because precisely in that year, they published an article 12 proposing a new equation: $\mathrm{PVR}_{\text {echo }}=\mathrm{TRV}^{2} / \mathrm{TVI}_{\mathrm{rvot}} \times 5-0.4$ 

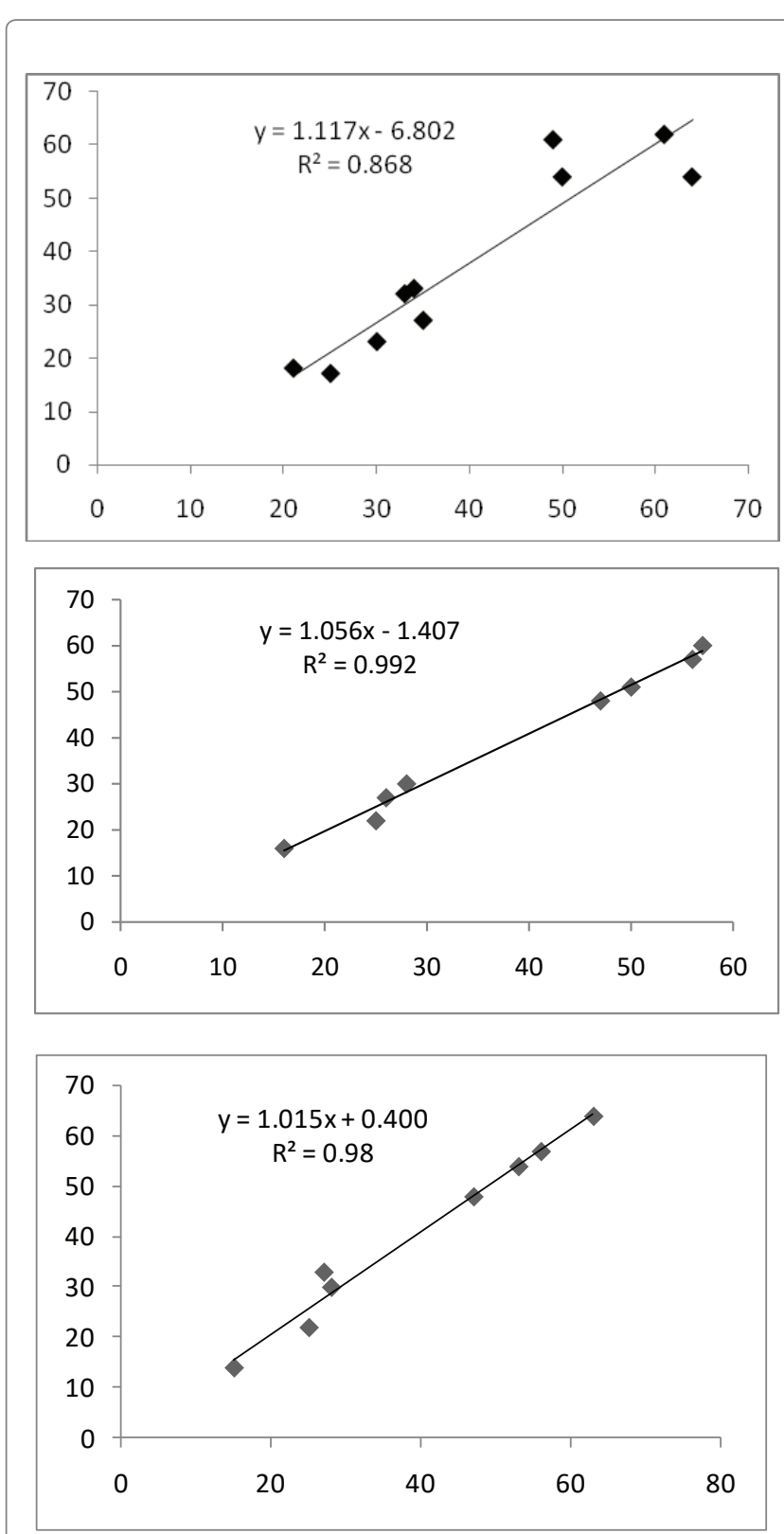

Figure 13: Linear regression analysis comparing the measurement by RHC and echocardiography [23] of the MPAP at time 0, 30 and recovery of the PVRT.

for patients with higher PVR who had a TRV/TVI ${ }_{\text {rvot }}$ index $\geq 0.275$, being this cut-off point for PVR $>6$ UW (ROC curve). Currently his two works have worldwide acceptance and recognition and $\mathrm{PVR}_{\text {echo }}$ equation=RTV/TVI ${ }_{\text {rvot }} \times 10+0.16$, is part of the list of hemodynamic variables validated and obtained by Doppler echocardiogram.

In a more current work (2017), Kaga S, et al. [16], proposed an equation based on the difference of the initial and final diastolic pressure gradient obtained by means of Pulmonary Regurgitation (PR) and CO: (early-diastolic PA-RV pressure gradient-end-diastolic PA-RV pressure gradient)/echocardiographic cardiac output. They analyzed the linear correlation between the Abbas equations (2003 and 2013) and the Scapellato equation with catheterization, obtaining
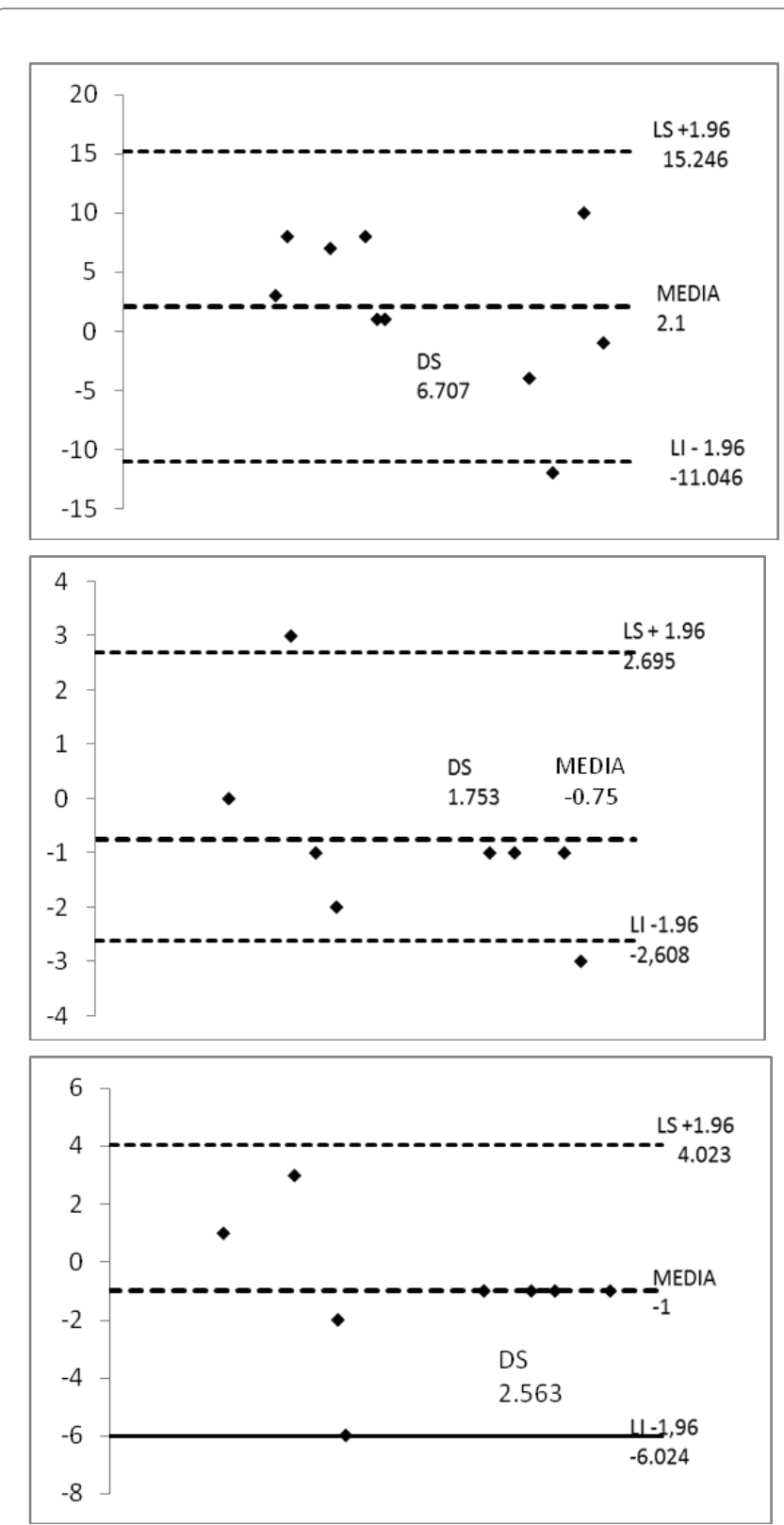

Figure 14: Bland Altman analysis showing satisfactory agreement limits between invasive and non-invasive methods [23] at the time 0.30 and recovery of TRVP.

correlation coefficients of 0.54 . 0.66 and 0.54 respectively. The best correlation with catheterization was obtained for the equation proposed in its work $\left(\mathrm{R}^{2}=0.81\right)$ followed by the index of Lindqvist (0.76) [39].

In the present work, with the first group of 20 patients, validated the usefulness of this equation, presenting a small discrepancy in the value of the correlation constant: $\mathrm{PVR}_{\text {echo }}=\mathrm{TRV} / \mathrm{TVI}_{\mathrm{rvot}} \times 10+0.36$. The analysis of Bland Altman showed limits of satisfactory concordance (mean +/-0.36, L: $0.12-0.61$ ). In the second part of the work were included 10 patients with clinical indication and echocardiographic of PVRT, analyzing mainly the recorded variations of PVR and MPAP, essential to establish the positivity of the test. The calculation of the 
MPAP was obtained by means of the equation proposed by Chemla $\mathrm{D}$, et al. [23]: $\mathrm{MPAP}=0.61 \times \mathrm{SPAP}+1.95$ and the PVR with the relationship TRV/TVI ${ }_{\text {rvot }}$ to evaluate its behavior in high values of PVR.

Two relevant findings were evidenced with the calculations: 1. The measurements of MPAP obtained by this formula were sustained similar to those reported by the catheterization in all phases of measurement of the test (t0, T30 and TR) with high linear correlation ( $\mathrm{t} 0 \mathrm{R}^{2}=0.87,0.99$ and 0.98 , respectively). 2. The correlation coefficient obtained when comparing the $\mathrm{PVR}_{\text {echo }}$ and $\mathrm{PVR}_{\text {cath }}$ values ascended from $\mathrm{R}^{2}=0.70$ to $\mathrm{R}^{2}=0.78$ when we applied the Abbas algorithm and in the cases with VRT/TVI ${ }_{\text {rvoy }}$ index $\geq$ 0.275 it increased even more when omitting the highest values, $\mathrm{R}^{2}=0.92(\mathrm{t} 0), \mathrm{R}^{2}=0.89$ ( $\mathrm{t} 30$ and $\left.\mathrm{tR}\right)$. The cut-off point (TRV/TVI $\mathrm{rvot}_{\mathrm{r}}$ $\geq 0.275$ ), specifies when in the linear regression analysis the correlation ceases to be linear to define the relationship between variables by an exponential growth curve, expressing the basis of the Abbas algorithm in its second work.

It's evident analyzes these finding that the $\mathrm{TVI}_{\text {rvot }}$ variable of the TRV/TVI ${ }_{\text {rvot }}$ index, is responsible for opening the widest gap between invasive and non-invasive methods. Very possibly by not taking into account the dilation of the right ventricle present in all cases of patients with elevation PVR $[40,41]$. It's thus that this work proposes an equation with reasoning more pathophysiologic than statistical, incorporating in its calculation. We also include a correction factor of the CO applicable in all patients according to the value of $\mathrm{TVI}_{\text {rvot }}$ that we call cfCOTVI ${ }_{\text {rvot }}$ suggested by the repeated observation of its decrease proportional to the degree of dilatation and systolic dysfunction of the RV. This corresponds approximately to the near value of the CO if we divide the TVI between 2 when its value is below $10 \mathrm{~cm}$, above this value, we will find normal values of $\mathrm{CO}(4-6 \mathrm{Lt} / \mathrm{min})$ allowing to standardize it to 5 . At the other end, TVI ${ }_{\text {rvot }}$ values below 6 would correspond to a very low $\mathrm{CO}$ estimate with probable severe right heart failure or shock (heart rate $(\mathrm{CI})<2.2 \mathrm{lt} / \mathrm{min} / \mathrm{mt}^{2}$ ).

The proposed equation is as follows:

$$
\begin{aligned}
& P V R_{\text {echo }}=\left[(\mathrm{TRV} \times \mathrm{RVD}) / \mathrm{TVI}_{\text {rvot }}\right] \times c f C O \mathrm{TVI}_{\text {rvot }}{ }^{*} \\
& T V I_{\text {RVOT }}<10 c f C O T V I_{R V O T}=T V I_{R V O T} / 2 \\
& \text { if } \mathrm{TVI}_{R V O T} \geq 10 c f C O \mathrm{TVI}_{\text {RVOT }}=5
\end{aligned}
$$

The linear regression analysis between the values obtained from PVR with this equation and that of Abbas with his algorithm reported a high correlation, $\mathrm{R}^{2}=0.97$, but when comparing the algorithms of Abbas, the PVRt with the RHC, we obtained a greater correlation with our proposal $\left(\mathrm{R}^{2}=0.84\right)$.

Limitations: low number of patients to perform the TRVP, however it is important to note that a total of 50 measurements were made. In all cases where it is not possible to measure the TRV or TVI ${ }_{\text {rvot }}$ it will not be possible to perform the PVR calculations, not representing the case of this investigation.

\section{Conclusions}

In this work we conclude: 1 . The algorithm of equations proposed by Abbas to determine PVR according to the relationship TRV/TVI is $\geq 0275$ is useful and easy to estimate [2]. The equation proposed in this work: $\mathrm{PVR}_{\text {echo }}=\left(\mathrm{TRV} \times \mathrm{RVD} / \mathrm{TVI}_{\text {rvot }}\right) \times \mathrm{cfCOTVI}_{\text {rvot }}$, is practical and applicable in all cases of pulmonary hypertension, representing an alternative to that offered by Abbas AE, et al. [13]. It's possible to perform the PVRT, TRVP through of Doppler echocardiography based on the high correlation found in this work between the values of MPAP and PVR when compared with the invasive method and echocardiographic.

\section{Recommendations}

Further studies of TRVP are recommended by comparing both methods (echocardiography, RHC) to give more statistical weight and validity to echocardiographic methods and therefore, the applicability in the test.

\section{Conflicts of Interest}

The authors of the present work do not declare conflicts of interest.

\section{Acknowledgement}

To God for giving us life and putting us on the path where sensitive people march with a high sense of vocation and service. To Dr. Rita Tamasaukas for advice on statistical analysis, revision and correction of the manuscript. To Ing. Daniela Gálatro for her collaboration in elaborating the tables and graphs of the linear regression analysis and Bland-Almant. To the Medical team, Technicians in echocardiography and nursing who work in the Departments of Cardiology and Intensive Therapy of the University Military Hospital "Dr. Carlos Arvelo."

\section{References}

1. Gómez-López EA (2017) Pulmonary hypertension associated with left heart disease: diagnostic and therapeutic approach. Rev Colomb Cardiol 24: 55-64.

2. Garrido-Lestache MEB, Gómez-Sánchez MA (2017) Therapeutic strategy in pulmonary arterial hypertension. Rev Colomb Cardiol 24: 41-47.

3. Ristow B, Shiller NB (2009) Stepping away from ritual right heart catheterization into the era of noninvasively measured pulmonary artery pressure. J Am Soc Echocardiogr 22: 820-822.

4. Farzaneh-Far R, McKeown BH, Dang D, Roberts J, Schiller NB, et al. (2008) Accuracy of Doppler-estimated pulmonary vascular resistance in patients before liver transplantation. Am J Cardiol 101: 259-262.

5. Conde-Camacho R, Cabrales-Arévalo J (2017) Right catheterization as a tool in the diagnosis of pulmonary hypertension. Rev Colomb Cardiol 24: 28-33.

6. Addonizio LJ, Gersony WM, Robbins RC, Drusin RE, Smith CR, et al. (1987) Elevated pulmonary vascular resistance and cardiac transplantation. Circulation 76: V52-V55.

7. Kirklin JK, Naftel DC, McGiffin DC, McVay RF, Blackstone EH, et al. (1988) Analysis of morbid events and risk factors for death after cardiac transplantation. J Am Coll Cardiol 11: 917-924.

8. DiSesa VJ, Cohn LH, Grossman W (1983) Management of adults with congenital bidirectional cardiac shunts, cyanosis, and pulmonary vascular obstruction: successful operative repair in 3 patients. Am J Cardiol 51: 1495-1497.

9. Galiè N, Humbert M, Vachiery JL, Gibbs S, Lang I, et al. (2016) 2015 ESC/ERS Guidelines for the diagnosis and treatment of pulmonary hypertension: The Joint Task Force for the Diagnosis and Treatment of Pulmonary Hypertension of the European Society of Cardiology (ESC) and the European Respiratory Society (ERS): Endorsed by: Association for European Paediatric and Congenital Cardiology (AEPC), International Society for Heart and Lung Transplantation (ISHLT). Eur Heart J 37: 67-119. 
10. Willard J, Richard A, Hillis L (1995) Cardiac Catheterization. In: Kloner RA (eds) The Guide to Cardiology. $3^{\text {rd }}$ edition, Le Jacq Communications, the University of Michigan 151.

11. Abbas AE, Fortuin FD, Schiller NB, Appleton CP, Moreno CA, et al. (2003) A simple method for noninvasive estimation of pulmonary vascular resistance. J Am Coll Cardiol 41: 1021-1027.

12. Abbas AE, Franey LM, Marwick T, Maeder MT, Kaye DM, et al. (2014) Noninvasive assessment of pulmonary vascular resistance by Doppler echocardiography. J Am Soc Echocardiogr 26: 1170-1177.

13. Haddad F, Zamanian R, Beraud AS, Schnittger I, Feinstein J, et al. (2009) A novel non-invasive method of estimating pulmonary vascular resistance in patients with pulmonary arterial hypertension. J Am Soc Echocardiogr 22: 523-529.

14. Gurudevan SV, Malouf PJ, Kahn AM, Auger WR, Waltman TJ, et al. (2007) Noninvasive assessment of pulmonary vascular resistance using Doppler tissue imaging of the tricuspid annulus. J Am Soc Echocardiogr 20: 1167-1171.

15. Scapellato $F$, Temporelli $P$, Eleuteri $E$, Corrà $U$, Imparato $A$, et al. (2001) Accurate noninvasive estimation of pulmonary vascular resistance by Doppler echocardiography in patients with chronic failure heart failure. J Am Coll Cardiol 37: 1813-1819.

16. Kaga S, Mikami T, Murayama M, Okada K, Masauzi N, et al. (2017) A new method to estimate pulmonary vascular resistance using diastolic pulmonary artery-right ventricular pressure gradients derived from continuous-wave Doppler velocity measurements of pulmonary regurgitation. Int J Cardiovasc Imaging 33: 31-38.

17. Opotowsky AR, Clair M, Afilalo J, Landzberg MJ, Waxman AB, et al. (2013) A simple echocardiographic method to estimate pulmonary vascular resistance. Am J Cardiol 112: 873-882.

18. Opotowsky AR, Ojeda J, Rogers F, Prasanna V, Clair M, et al. (2012) A simple echocardiographic prediction rule for hemodynamics in pulmonary hypertension. Circ Cardiovasc Imaging 5: 765-775.

19. Santos-Martínez LE, Contreras-Rodríguez A, Moreno-González A, Medina-Concebidac LE, Rodríguez-Almendros NA, et al. (2017) It is useful to evaluate pulmonary vascular reactivity of echocardiography in the pulmonary hypertension? A challenge to solve. Arch Cardiol Mex 87: 260-262.

20. Mitchell C, Rahko PS, Blauwet LA, Canaday B, Finstuen JA, et al. (2019) Guidelines for Performing a Comprehensive Transthoracic Echocardiographic Examination in Adults: Recommendations from the American Society of Echocardiography. J Am Soc Echocardiogr 32: 1-64.

21. Yock PG, Popp RL (1984) Noninvasive estimation of right ventricular systolic pressure by Doppler ultrasound in patients with tricuspid regurgitation. Circulation 70: 657-662.

22. Velazco CLE (2009) Role of echocardiography in the study of pulmonary arterial hypertension. Avances Cardiol 29: 154-164.

23. Chemla D, Castelain V, Humbert M, Hébert J, Simonneau G, et al. (2004) New formula for predicting mean pulmonary artery pressure using systolic pulmonary artery pressure. Chest 126: 1313-1317.

24. Reuter DA, Huang C, Edrich T, Shernan SK, Eltzschig HK (2010) Cardiac output monitoring using indicator-dilution techniques: basics, limits, and perspectives. Anesth Analg 110: 799-811.

25. Celermajer DS, Marwick T (2008) Echocardiographic and right heart catheterization techniques in patients with pulmonary arteria hypertension. Int J Cardiol 125: 294-303.
26. López AC, Sala MF, Salgado AR (2010) The current role of the SwanGanz catheter. Med Intensiva 34: 203-214.

27. Rich JD, Archer SL, Rich S (2013) Noninvasive cardiac output measurements in patients with pulmonary hypertension. Eur Respir J 42: 125-133.

28. Senior $M$, Muñoz E, Arévalo $E$, Tamayo N, Fernández $A$, et al (2016) Proof of vasoreactivity with iloprost in pulmonary arterial hypertension. Act med Colomb 41: 229-234.

29. Robledo P, Rosas R, Campos C, Morales B (2006) Pulmonary vascular reactivity Test. Neumol Cir Torax 65: 43-50.

30. Sitbon O, Humbert M, Jaïs X, loos V, Hamid AM, et al. (2005) Longterm response to calcium channel blockers in idiopathic pulmonary arterial hypertension. Circulation 111: 3105-3111.

31. Cerda J, Cifuentes L (2012) Using ROC curves in clinical investigation: theoretical and practical issues. Rev Chilena Infectol 29: 138-141.

32. Vlahos AP, Feinstein JA, Schiller NB, Silverman NH (2008) Extension of Doppler-derived echocardiographic measures of pulmonary vascular resistance to patients with moderate or severe pulmonary vascular disease. J Am Soc Echocardiogr 21: 711-714.

33. Bidart CM, Abbas AE, Parish JM, Chaliki HP, Moreno CA, et al (2007) The noninvasive evaluation of exercise-induced changes in pulmonary artery pressure and pulmonary vascular resistance. J Am Soc Echocardiograph 20: 269-275.

34. Farzaneh-Far R, McKeown B, Dang D, Roberts J, Schiller N, et al. (2008) Accuracy of Doppler-estimated pulmonary vascular resistance in patients before liver transplantation. Am J Cardiol 101 259-262.

35. Kouzu H, Nakatani S, Kyotani S, Kanzaki H, Nakanishi N, et al. (2009) Noninvasive estimation of pulmonary vascular resistance by Doppler echocardiography in patients with pulmonary arterial hypertension. Am J Cardiol 103: 872-876.

36. Carrellán AJO, Japan MR, Hernández FG, Haldón JEL, Medina CO, et al. (2010) Calculation of pulmonary vascular resistance by stress echocardiography as a simple method for early detection of pulmonary hypertension. Rev Esp Cardiol 3: 37.

37. Arkles JS, Opotowsky AR, Ojeda J, Rogers F, Liu T, et al. (2013) Shape of the right ventricular Doppler envelope predicts hemodynamics and right heart function in pulmonary hypertension. Am J Respir Crit Care Med 183: 268-276.

38. Yan C, Xu Z, Jin J, Lv J, Liu Q, et al. (2015) A feasible method for non-invasive measurement of pulmonary vascular resistance in pulmonary arterial hypertension: Combined use of transthoracic Doppler-echocardiography and cardiac magnetic resonance. Noninvasive estimation of pulmonary vascular resistance. Int J Cardiol Heart Vasc 9: 22-27.

39. Lindqvist P, Söderberg S, Gonzalez MC, Tossavainen E, Henein MY (2011) Echocardiography based estimation of pulmonary vascular resistance in patients with pulmonary hypertension: a simultaneous Doppler echocardiography and cardiac catheterization study. Eur J Echocardiogr 12: 961-966.

40. Pérez CD, Alonso HA, Gómez GY, Novo CLE, Cruz EJM (2012) Echocardiographic Variables for bloodless evaluation of pulmonary hemodynamics. Cor Salud 4: 201-215.

41. Hovnanian A, Menezes E, Hoette S, Jardim C, Jasinowodolinski D, et al. (2011) The role of imaging techniques in the assessment of pulmonary circulation. J Brasil Pneumol 37: 389-403.

Citation: Muñoz-Hernández TT, Hirschhaut-Schor E, Tovar-Blanco SF, Lara-Boada GJ (2019) The Age of Non-Invasive Measurements: Echocardiographic Equations Methods to Determine Variables in the Pulmonary Vascular Reactivity Test. J Surg Open Access 5(6): 